\title{
Health benefits of resveratrol administration
}

\author{
Sabina Galiniak ${ }^{\varpi}$, David Aebisher and Dorota Bartusik-Aebisher \\ Faculty of Medicine, Rzeszów University, Rzeszów, Poland
}

Resveratrol is a polyphenol that is abundant in grape skin and seeds. Food sources of resveratrol include wine, berries, and peanuts. This compound has many properties, including activity against glycation, oxidative stress, inflammation, neurodegeneration, several types of cancer, and aging. Because resveratrol is generally welltolerated, it is believed to be a promising compound in preventing many diseases, such as diabetes and its complications. Unfortunately, this compound exhibits low bioavailability and solubility. The aim of this review is to summarize the latest information on the multiple effects of resveratrol on health and the benefits of its intake, based on in vitro and in vivo studies in animals and humans.

Key words: resveratrol, glycation, oxidative stress, polyphenol

Received: 01 December, 2018; revised: 29 January, 2019; accepted: 01 February, 2019; available on-line: 28 Fabruary, 2019

छe-mail: sgaliniak@ur.edu.pl

Abbreviations: AGEs, advanced glycation end products; MGO, methylglyoxal; GO, glyoxal; HSA, human serum albumin; BSA, bovine serum albumin; AOPP, advanced oxidation protein products; ROS, reactive oxygen species; MDA, malondialdehyde; CAT, catalase; SOD, superoxide dismutase; IL, interleukin; TNF-a, tumor necrosis factor $a ; N F K B$, nuclear factor $K B$; IKB, inhibitor of $K B$; JAK/ STAT, Janus kinases/signal transducer and activator of transcription; PI3K, phosphatidylinositol-3-kinases; Akt, protein kinase $\mathrm{B}$; $\mathrm{Bcl}-2$, B-cell lymphoma 2; Bax, Bcl-2-associated $\mathrm{X}$ protein

\section{INTRODUCTION}

Resveratrol (3,5,4'-trans-trihydroxystilbene) is a polyphenolic phytoalexin belonging to the stilbene family. It is a natural dietary plant compound that occurs mainly in grape skin and seeds but is also found in wines and various other types of plant foods, especially peanuts, berries, and tea (Shrikanta et al., 2015). Resveratrol is synthesized by more than 70 species of plants in response to infection, stress, injury, bacteria or fungal infections, and UV-irradiation (Hasan \& Bae, 2017). Synthesis of this molecule in plants is catalysed by resveratrol synthase in the phenylpropanoid pathway in a process similar to that of flavonoids (Kapetanovic et al., 2011). Resveratrol was first reported and isolated from white hellebore by a Japanese researcher Takaoka in 1939 (Takaoka, 1939). Resveratrol possesses two phenol rings (monophenol and diphenol) bonded together by a double styrene bond and it exists in both cis and trans isomeric forms. Trans-resveratrol (Scheme 1) appears to be the more abundant and stable natural form (Gambini et al., 2015). This molecule has three hydroxyl groups which are involved in free radical scavenging and metal chelation (Caruso et al., 2004; Gülçin, 2010). The presence of hydroxyl groups also facilitates interaction with macromolecules.<smiles>Oc1ccc(/C=C/c2cc(O)cc(O)c2)cc1</smiles>

Scheme 1. Structure of trans-resveratrol.

Resveratrol reveals a wide range of biological properties including anti-glycation, antioxidant, anti-inflammation, neuroprotective, anti-cancer, and anti-aging activity in various in vitro and in vivo experimental models (Öztürk et al., 2017; Rauf et al., 2017; Jardim et al., 2018; Li et al., 2018; Salehi et al., 2018). Currently, resveratrol research spans a large spectrum of areas and is a subject of considerable scientific attention, in particular, investigations of its biological activity and the effects of resveratrol administration in numerous diseases in both clinical and nonclinical trials (Scheme 2).

\section{SELECTED BIOLOGICAL PROPERTIES OF RESVERATROL}

\section{Antiglycation activity}

Glycation is a nonenzymatic reaction between proteins and reducing sugars, leading to the formation of advanced glycation end products (AGEs). Advanced glycation end products accumulate and cause damage at the tissue and cellular level, including lipid peroxidation, endothelial dysfunction, changes in protein structure, and

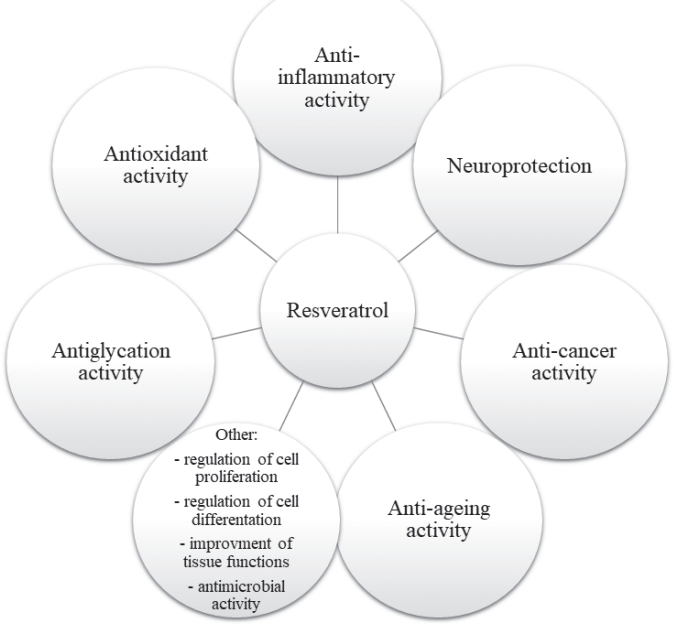

Scheme. 2. The activities of resveratrol on health. 
stimulation of inappropriate cellular activity (Singh et al., 2001; Galiniak et al., 2017). Glycation produces highly reactive dicarbonyl compounds such as methylglyoxal and glyoxal, which are key precursors to the formation of AGEs. Methylglyoxal (MGO) is also generated by glycolysis, glucose autooxidation, and lipid peroxidation, while glyoxal (GO) is formed during lipid peroxidation and degradation of monosaccharide and saccharide derivatives. Both MGO and GO are known to enhance oxidative stress in the human body. Recent reports suggest that increased glycation is associated with a higher prevalence of diabetes and related complications (Adamska et al., 2018; Rhee \& Kim, 2018), lung (Khan et al., 2018) and breast cancer (Walter et al., 2018), myasthenia gravis (Adamczyk-Sowa et al., 2017), and neurodegenerative diseases (Pinkas \& Aschner, 2016).

Increasingly, evidence indicates that compounds of natural origin, especially polyphenols, have antiglycation properties. Among effective glycation inhibitors are phenolic acids, naringin, genistein, rutin, quercitrin, and kaempferol (Sadowska-Bartosz et al., 2014; Yeh et al., 2017). Many reports have confirmed that resveratrol displays antiglycation activity as well.

A high percentage (up to 99\%) of resveratrol-induced inhibition of AGE production was demonstrated by Shen and others (Shen et al., 2017) in BSA/fructose, $\mathrm{BSA} / \mathrm{MGO}$, and arginine/MGO mixtures. Resveratrol inhibition of AGE and binding to toxic MGO and GO have demonstrated both anti-oxidative and pro-oxidative effects, as resveratrol adducts can lead to the oxidation of amino acids in human serum albumin (HAS) (Arcanjo et al., 2018). Furthermore, resveratrol reveals antiglycation activity against the harmful effect of AGEs or $\alpha$-dicarbonyls on porcine chondrocytes (Liu et al., 2010), mouse oocytes (Liu et al., 2013), and dendritic cells obtained from peripheral blood mononuclear cells (Buttari et al., 2013).

Yilmaz and others (Yllmaz et al., 2017) has shown that administration of resveratrol in drinking water to chronic MG-treated rats significantly reduces the level of advanced oxidation protein products (AOPP), AGEs, and protein carbonyl in plasma, as well as markers of oxidative stress in the liver. A significant decrease in urine albumin and creatinine and an increase in serum antioxidant enzymes were also observed in patients with type II diabetes and diabetic nephropathy who received resveratrol at the dose of $500 \mathrm{mg}$ per day (Sattarinezhad et al., 2018). Resveratrol prevents opacification and formation of polyols in the bovine lens, as well as ameliorates kidney function due to suppression of AGEs formation, suggesting that resveratrol may be considered as a protective agent against diabetic complications such as cataracts and nephropathy (Ciddi \& Dodda, 2014; Hussein \& Mahfouz, 2016). Furthermore, resveratrol is a prospective therapeutic agent against diabetic ototoxicity (Erkan et al., 2018), renal fibrosis (He et al., 2016), progression of cataracts (Higashi et al., 2018), and bone density loss in patients with type 2 diabetes (Bo et al., 2018). Likewise, resveratrol is also involved in protection against diabetic cardiomyopathy development via improvement of mitochondrial function and inhibition of apoptosis of cardiomyocytes (Diao et al., 2018). Resveratrol preserves pancreatic tissue by reducing inflammatory factors and glucose levels in serum, and ultimately leads to the protection of cardiovascular tissues in diabetic rat models of coronary heart disease (Huo et al., 2019).

Similarly, it has been shown that by modulating the switching between apoptosis and autophagy resveratrol has a beneficial effect on cardiomyopathy induced in car- diac myoblast cells exposed to the combination of high glucose and palmitate (Xu et al., 2018). Guzmán and others (Guzmán et al., 2018) noted that resveratrol at a dose of 1,10 and $100 \mu \mathrm{M}$ has a protective effect on acute high glucose-induced damage in endothelial cells. Moreover, resveratrol attenuates methylglyoxal induced endothelial damage by promoting the expression and activity of endothelial nitric oxide synthase in thoracic aorta in older rats (Tasatargil et al., 2018). In diabetic mice receiving resveratrol, a decrease in the level of apoptosis of glomerular podocytes and renal tubular epithelial cells was noted (Zhang et al., 2018). The diabetic rats treated with resveratrol had reduced levels of factors related to endoplasmic reticulum stress which underlies the progression of diabetic nephropathy (Yuan et al., 2018).

In summary, the results indicate that resveratrol may be considered as a beneficial anti-glycation agent in in vitro and in vivo experiments as well as in the treatment of diseases associated with increased glycation.

\section{Antioxidant activity}

Oxidative stress is defined as an imbalance between generation of reactive oxygen species and the antioxidant defence in favor of oxidant production. Enhanced oxidative stress damages macromolecules and impairs their functions, which underlies many age-related diseases including cancer, diabetes, chronic kidney disease, cardiovascular and neurodegenerative diseases (Liguori et al., 2018). Moreover, overproduction of ROS induces inflammation, dysregulation of mitochondria and cell death (Wu et al., 2018). Also, it was shown that autooxidation of glucose may contribute to excessive ROS production and intensification of oxidative stress (Matough et al., 2012). Resveratrol is confirmed to be a powerful antioxidant which activity is associated with presence of three hydroxyl groups in its structure. Resveratrol has an inhibitory effect on excessive ROS production, aberrant mitochondrial distribution, and lipid peroxidation (Liu et al., 2013; Liguori et al., 2018). Treatment of primary epidermal keratinocytes with resveratrol leads to a 1.3fold increase of endogenously generated glutathione and quantitative reduction of the cellular redox environment and endogenous ROS production (Plauth et al., 2016). In astroglial cells treated with ammonia, resveratrol prevents both an increase in ROS production and a decrease of mitochondrial membrane potential, which indicates a role in maintaining cellular redox homeostasis (Bobermin et al., 2018). In fibroblasts exposed to rotenone, resveratrol decreases mitochondria fragmentation and maintains the potential of the mitochondrial membrane, as well as prevents the attenuation of oxidative phosphorylation, thus exerting a protective effect against the harmful impact of ROS (Sgarbi et al., 2018). Recent study by Cheng and others (Cheng et al., 2019) revealed that resveratrol prevents hepatic steatosis in obese mice fed a high-fat diet by reducing oxidative stress and inflammation. The protective effect of resveratrol against hepatic steatosis is supported by lowering the accumulation of lipid droplets in hepatocytes (Zhou et al., 2018).

Furthermore, resveratrol treatment of the epithelial cells protects them from oxidative damage induced by hydrogen peroxide and promotes the expression and phosphorylation of occludin and other zonula occludens proteins. This protection is caused by reducing MDA and intracellular ROS concentration and increasing expression levels of antioxidant enzymes (Wang et al., 2016). The protective effects of chronic administration of resveratrol against AGE-induced oxidative stress and 
apoptosis, together with the improvement of glucose tolerance, are also observed in pancreatic cells in mice with type 2 diabetes (Lee et al., 2012; Ginés et al., 2017).

Resveratrol intake by diabetic rats at a dose of $5 \mathrm{mg} /$ $\mathrm{kg} /$ day leads to normalization of antioxidant status, exacerbated by oxidative stress induced by hyperglycemia (Hussein \& Mahfouz, 2016). Administration of resveratrol at a dose of 10 or $20 \mathrm{mg} / \mathrm{kg}$ for 4 weeks in rats with a streptozotocin-induced diabetes results in a reduction in the content of AOPP and MDA as well as catalase (CAT) and superoxide dismutase (SOD) activity in the lens compared to untreated diabetic rats (Sedlak et al., 2018). Resveratrol-treated animals have reduced production of ROS, elevated membrane potential, and inhibition of cytochrome c release from the inner mitochondrial membrane (Zhang et al., 2018). Wang and others (Wang et al., 2018) observed that resveratrol counteracted the accumulation of 3-nitrotyrosine and generation of 4-hydroxynonenal during the development of diabetes mellitus-induced cardiomyopathy. Resveratrol-treated rats with diabetes have a significant decrease in the MDA level and total oxidant level, as well as an increase in total antioxidant capacity (Moridi et al., 2015; Khazaei et al., 2016) when compared to untreated groups. Moreover, resveratrol protects the spinal cord from ischemic damage in rats by reducing plasma levels of nitrite, AOPP and MDA, and increasing the enzymatic activity of SOD and CAT (Fu et al., 2018). Resveratrol also attenuates oxidative stress in rats with experimental periodontitis (Corrêa et al., 2018), induced early Alzheimer's disease (Lin et al., 2018) and chronic obstructive pulmonary disease (Wang et al., 2017).

The studies mentioned above indicate that resveratrol has a therapeutic effect in cell and animal experiments involving increased oxidative stress, which is associated to the limitation of ROS generation and stimulation of compounds that act as an antioxidant barrier.

\section{OTHER BIOLOGICAL ACTIVITIES OF RESVERATROL}

\section{Anti-inflammatory activity}

Resveratrol suppresses IL-6 transcription and translation, resulting in attenuation of its secretion by macrophages (Ohtsu et al., 2017). Likewise, the administration of resveratrol to monocyte cultures leads to a reduction in the expression of inflammatory mediators: TNF- $\alpha$ and IL-8, without inducing cytotoxicity (Pinheiro et al., 2018). Resveratrol significantly inhibits the production of extracellular matrix proteins by pancreatic stellate cells, which are involved in the development of pancreatic fibrosis (Xia et al., 2018). Furthermore, resveratrol is involved in the inhibition of toll-like receptors, which in their active form can induce proinflammatory cytokines and chemokine expression and stimulate the activation of innate and adaptive immunity (Chen et al., 2018). Resveratrol reduces matrix-metalloprotease expression and supresses the production of IL-1, IL- 6 and TNF- $\alpha$ in a dose dependent manner in chondrocytes with induced osteoarthritis (Li et al., 2018). Moreover, resveratrol treatment in patients after oral implantology reduces serum levels of IL-1 $\beta$, IL-17A and TNF- $\alpha$ while the levels of IL-2, IL-6 and IL-10 are elevated (BaGen et al., 2018). Ma and others (Ma et al., 2015) observed that resveratrol effectively suppresses $\mathrm{NF}-x \mathrm{~B}$ signaling through inhibiting the activities of $\mathrm{NF}-x \mathrm{~B}$ and $\mathrm{I} \varkappa \mathrm{B}$ kinase, as well as by suppressing the phosphorylation of JAK/STAT signalling pathways. Resveratrol shows protective activity against intestinal ischemia-reperfusion injury by inhibiting mast cells from degranulation and decreasing apoptosis of intestinal epithelial cells, which prevents overall organ dysfunction (Zhao et al., 2018).

Anti-inflammatory activities of resveratrol are observed also in case of hyper-acute small intestinal inflammation (Bereswill et al., 2010) as well as in immune-mediated diseases (Švajger \& Jeras, 2012). Moreover, it prevents acceleration of cholesterol accumulation and disturbances of macrophage lipid homeostasis after induction by glycation products (Zhang et al., 2010).

\section{Neuroprotection}

Resveratrol is also involved in the reduction of neuronal damage and apoptosis and the improvement of the central nervous system function. Resveratrol has been shown to reduce neurodegeneration in the murine cerebral cortex and enhance memory recovery after exposure to fluoride (Sharma et al., 2018). Also, the administration of resveratrol improves cognition, learning and memory in rats with vascular dementia (Ma et al., 2013). Report by Corpas and others (Corpas et al., 2018) indicates that resveratrol also improves cognition and induces neuroprotection in amyloid and tau pathologies in mice models of Alzheimer's disease. However, results of resveratrol supplementation in human are inconsistent. A meta-analysis of randomized controlled trials suggests that resveratrol may be beneficial (Marx et al., 2018) or may have no significant impact on the selected measures of cognitive performance (Farzaei et al., 2018). Several neuroprotective properties of resveratrol have been suggested in the studies of its effects in the intracerebral hemorrhage (Bonsack et al., 2017), cerebral neurodamage (Nalagoni \& Karnati, 2016), and central nervous system injuries such as stroke (Lopez et al., 2015). Likewise, resveratrol shows a neuroprotective effects in cerebral ischemia/reperfusion injury in rat brain by reducing the cerebral infract volume and stimulating the expression of components of the intracellular signaling pathway including kinases such as JAK2, PI3K or Akt and anti-apoptotic molecules, while downregulating the expression of pro-apoptotic caspase-3 and Bax (Hou et al., 2018).

Resveratrol also alleviates neuropathic pain in mice through repressing the expression of proinflammatory cytokines and increasing the expression of anti-inflammatory IL-10 (Tao et al., 2016). Similarly, the observed beneficial effect of resveratrol on hyperalgesia in rats with chronic neuropathic pain is due to the inhibition of the expression of glial fibrillary acidic protein and the P2X7 receptor, a key player in nervous pathological pain (Xie et al., 2017). In addition, resveratrol at the dose of $10-80 \mathrm{mg} / \mathrm{kg}$ per day may be an effective treatment for depression in animal models (Moore et al., 2018). There is also evidence that the neuroprotective effect is also enhanced by the antioxidant and anti-inflammatory properties of resveratrol.

\section{Anti-cancer activity}

Many in vitro and in vivo studies suggest that resveratrol has anti-cancer properties due to its wide range of activities, including antioxidant effects and regulating the expression of pro-apoptotic proteins, as well as molecules underlying tumor development. Resveratrol is known to reduce the incidence and development of various types of cancer, such as cervical (Zhou et al., 2018), pancreatic (Zhao et al., 2018), gastric (Wu et al., 2018), breast and colorectal (Lucas et al., 2018), as well as thyroid cancer 
(Zheng et al., 2018). Research results indicate that resveratrol has protective effect on the normal cells, while inducing death in cancer cells. This can be associated with different cellular targets and metabolic pathways of resveratrol in healthy and cancerous cells. In addition, this dual pattern of resveratrol action depends on the dose. Lower concentrations increase expression of cell survival proteins, whereas higher doses stimulate cell apoptosis or necrosis regardless of whether the cell is healthy or pathological (Szende et al., 2010; San Hipólito-Luengo et al., 2017). Resveratrol at a high dose inhibits synthesis of nucleic acids and proteins, leads to impairment of chromatin structure, and finally, causes cell death (Mukherjee et al., 2010).

Monteillier and others (Monteillier et al., 2018) showed that intranasal administration of $60 \mathrm{mg} / \mathrm{kg}$ resveratrol to mice with induced lung cancer caused a notable decrease in the tumor multiplicity and volume via enhanced apoptosis. Moreover, treating gastric cancer cells with resveratrol elevated the levels of pro-apoptotic proteins such as Bax, while the levels of anti-apoptotic proteins such as $\mathrm{Bcl}-2$ were decreased compared to untreated controls (Wu et al., 2018). Treatment of osteosarcoma cells with $20 \mu \mathrm{M}$ resveratrol results in reduction of cell viability, decrease in self-renewing and tumorigenesis via inhibition of intracellular STAT3 signaling and cytokine synthesis (Peng \& Jiang, 2018). In general, the anti-cancer activity of resveratrol is based on the suppression of the expression of proteins involved in carcinogenesis, such as phospholipid scramblase 1 (Zhou et al., 2018), stimulation of caspase 3 cleavage (Lucas et al., 2018) and activation of the mitochondrial ROS signaling pathway (Zheng et al., 2018). Furthermore, resveratrol inhibits the cell cycle by inducing S-phase arrest in gastric cancer cells in a dose- dependent manner (Wu et al., 2018). Resveratrol has also been found to increase the effect of anticancer drugs and decrease drug resistance in cancer cells (Hallajian et al., 2018; Pouyafar et al., 2019). Taken together, in vivo and in vitro studies confirm the beneficial antitumor effect of resveratrol.

\section{Anti-ageing activity}

Resveratrol has been reported to extend life span in several different subjects including the fish species Nothobranchius furzeri (Valenzano et al., 2006) and Nothobranchius guentheri (Liu et al., 2015), as well as Drosophila melanogaster (Wang et al., 2013), honey bee (Rascon et al., 2012) and mice (Baur et al., 2006). Roggerio and others (Roggerio et al., 2018) observed that administration of resveratrol (500 mg/day) in healthy and slightly overweight subjects resulted in higher gene expression and serum concentration of sirtuin-1. Sirtuins exhibit a broad spectrum of activity, including anti-ageing and anti-inflammatory effects, inhibition of degenerative disorders such as liver steatosis, as well as improvement of endothelial function, and prevention of cancer (Watroba \& Szukiewicz, 2016). Recent report shows that short-term injection of resveratrol in postovulatory oocyte delayed the aging process of oocytes in middle-aged mice by promoting the expression of sirtuin-1, reducing ROS generation, and ameliorating mitochondrial function (Liang et al. 2018). Generally, the mechanisms of resveratrol prolongevity activity are similar to caloric restriction (Bass et al., 2007).

Despite a number of studies that demonstrate the lifeextending activity of resveratrol, its anti-ageing properties are still controversial due to the growing number of reports to the contrary. Recently, Ramos-Gomez and oth- ers (Ramos-Gomez et al., 2017) described that resveratrol caused mitochondrial dysfunction and reduction in the chronological life-span of Sacharomyces cerevisiae. Similarly, it is known that dietary resveratrol does not extend the life span of the mosquito Anopheles stephensi (Johnson \& Riehle, 2015) nor Drosophila melanogaster and does not influence gene expression of longevity-associated and antioxidant enzymes (Staats et al., 2018). Wang et al. (2013) suggested that the life-extending effect of resveratrol depends on dietary composition, dose and gender. Their results indicate that resveratrol at a dose of $400 \mu \mathrm{M}$ has a prolongevity effect on females of Drosophila melanogaster fed a high fat diet. However, a lower resveratrol (or fat?) concentration had no effect on the lifespan of female flies fed a (fat? calorie?) restricted diet or diet rich in sugar and protein. Similarly, it was indicated that the life-extending activities of resveratrol depended on the model organism and its genetic background (Pallauf et al., 2016).

Besides the aforementioned effects of resveratrol, it exhibits additional beneficial activities on other targets at the cellular and tissue levels. A report by Hara and others (Hara et al., 2018) suggests that resveratrol attenuates changes induced in bovine embryos composed of 8-12 cells by vitrification due to degradation of damaged mitochondria, without affecting ATP content and activation of further embryonic development. Gorga and others (Gorga et al., 2018) observed that resveratrol decreased expression of cyclins and activated sirtuin 1, which lead to regulation of immature Sertoli cells proliferation. Resveratrol also acts as an activator of Notch signalling and an inhibitor of endothelial cell proliferation and migration (LaFoya et al., 2019).

Resveratrol induces neuronal differentiation in murine neuroblastoma cells (Namsi et al., 2018) and differentiation of monocytes to macrophages (Vasamsetti et al., 2016). Recent reports show that resveratrol increases self-renewal and maintains the pluripotency of human and mouse embryonic stem cells (Li et al., 2017; Safaeinejad et al., 2017). Intragastric administration or resveratrol causes activation of cardiac stem cells, an increase of capillary density, and reduction of apoptosis of cardiomyocytes, which may be beneficial in myocardial regeneration after acute myocardial infarction (Ling et al., 2017). Furthermore, by reducing the expression of perilipin 5, resveratrol accelerates lipid hydrolysis in brown adipose tissue, which may cause a decrease in weight and myocardial steatosis of heart tissue (Mehdi et al., 2018). Resveratrol also exhibits antimicrobial activity against Haemophilus influenzae (Euba et al., 2017), Escherichia coli (Subramanian et al., 2014), Propionibacterium acnes (Taylor et al., 2014), and Staphyloccocus aureus (Wu \& Huang, 2017). Toniolo et al. (2018) observed that supplementation with $0.04 \%$ resveratrol for six months also improves the resistance to fatigue and functional-mechanical properties of skeletal muscles in aged mice. Furthermore, resveratrol at a dose of $500 \mathrm{mg}$ per day attenuates joint pain and improves functional activity of patients with knee osteoarthritis (Hussain et al., 2018; Marouf et al., 2018). Farrokhi and others (Farrokhi et al., 2018) demonstrated that $120 \mu \mathrm{M}$ resveratrol reduced production of matrix metalloproteinase 9, which makes it a potential therapeutic agent in atherosclerosis. Resveratrol also has a beneficial effect in counteracting allergic asthma (Alharris et al., 2018), as well as anxiety and depression disorders (Liu et al., 2019). Moreover, resveratrol improves testosterone levels and sperm parameters by reducing apoptosis in testes (Shatti, 2018). 
Unfortunately, despite numerous reports presenting a beneficial effect of resveratrol treatments on many diseases or pathological states, it has poor bioavailability and water solubility (less than $0.05 \mathrm{mg} / \mathrm{ml}$ ). Reports indicate that a $25 \mathrm{mg}$ intake of resveratrol resulted in plasma concentrations lower than $10 \mathrm{ng} / \mathrm{ml}$, while concentrations of $500 \mathrm{ng} / \mathrm{ml}$ in plasma were measured after a high dose of $5000 \mathrm{mg}$ (Walle, 2011). Sergides and others (Sergides et al., 2016) showed that intake of $500 \mathrm{mg}$ of resveratrol in the form of tablets was welltolerated and led to plasma concentrations of about $70 \mathrm{ng} / \mathrm{ml}$. Other studies also confirm that administration of resveratrol is generally well-tolerated and safe (Sergides et al., 2016; Berman et al., 2017), although some adverse effects were reported when resveratrol was given in high doses (Novelle et al., 2015). Diarrhoea, nausea, anemia, vomiting, flatulence, abdominal discomfort as well as renal failure via cast and crystal nephropathy and acute tubular damage are among the most common side effects of resveratrol, however, the nephrotoxic effect of resveratrol occurred only in patients with multiple myeloma (Brown et al., 2010; la Porte et al., 2010; Popat et al., 2013). A recent study showed that incubation of human placental explants with resveratrol at a dose up to $100 \mu \mathrm{M}$ led to impairment of fatty acid uptake and oxidation of placental tissue, which may negatively affect fetal development (Landau et al., 2017). Kumaran and others (Kumaran et al., 2018) also demonstrated that oral resveratrol tablet taken once a day induced thrombocytopenia in woman with melasma.

Resveratrol has a short half-life of approximately $1.5 \mathrm{~h}$ due to rapid absorption in the intestine and degradation in the liver (Marier et al, 2002). After consumption, 77$80 \%$ of resveratrol is absorbed into the blood stream by active transport via intestinal epithelial cells, after which it binds to albumin and lipoproteins. This polyphenol is easily released from the complexes and can be transported into cells. About $49-61 \%$ of resveratrol is excreted in the urine (Soleas et al., 2001).

To improve the bioavailability of this compound, more complex formulations have been prepared, including nanoparticles and nanostructured lipid carriers containing resveratrol (Gokce et al., 2012; Peñalva et al., 2018). Enhancing resveratrol bioavailability was also attempted in rats by treating them with 3,5,4'-tri-O-acetylresveratrol (TARES), an acetylated resveratrol prodrug that can be enzymatically hydrolyzed to free trans-resveratrol in cells (de Vries et al., 2018).

\section{CONCLUSION}

Overall, resveratrol has potential benefits for human health and exhibits protective effects against glycation, free radicals' production, neurodegeneration, inflammation, and tumor development. Life-extending properties of resveratrol are still controversial, however, there is evidence suggesting anti-ageing activity. The main mechanisms of resveratrol activity are based on the prevention of apoptosis and ROS production by downregulation of expression of anti- or proapoptotic proteins involved in antioxidant barrier systems, and improvements in mitochondrial function.

Nonetheless, more research, especially clinical trials on large number of patients are still needed for unambiguous confirmation of its positive action. Future research should also focus on improving resveratrol bioavailability and counteracting any adverse effects after administration.

\section{REFERENCES}

Adamczyk-Sowa M, Bieszczad-Bedrejczuk E, Galiniak S, Rozmiłowska I, Czyżewski D, Bartosz G, Sadowska-Bartosz I (2017) Oxidative modifications of blood serum proteins in myasthenia gravis. J Neuroimmunol 305: 145-153. https://doi.org/10.1016/j.jneuroim.2017.01.019

Adamska A, Araszkiewicz A, Pilacinski S, Gandecka A, Grzelka A, Kowalska K, Malinska A, Nowicki M, Zozulinska-Ziolkiewicz D (2018) Dermal microvessel density and maturity is closely associated with atherogenic dyslipidemia and accumulation of advanced glycation end products in adult patients with type 1 diabetes. Microvasc Res 121: 46-51. https://doi.org/10.1016/j.mvr.2018.10.002

Alharris E, Alghetaa H, Seth R, Chatterjee S, Singh NP, Nagarkatti M, Nagarkatti P (2018) Resveratrol attenuates allergic asthma and associated inflammation in the lungs through regulation of miRNA34a that targets FoxP3 in mice. Front Immunol 9: 2992. https://doi. org/10.3389/fimmu.2018.02992

Arcanjo NMO, Luna C, Madruga MS, Estévez M (2018) Antioxidant and pro-oxidant actions of resveratrol on human serum albumin in the presence of toxic diabetes metabolites: Glyoxal and methylglyoxal. Biochim Biophys Acta Gen Subj 1862: 1938-1947. https://doi. org/10.1016/j.bbagen.2018.06.007

BaGen H, Liu X, Han J (2018) The anti-inflammation effects of resveratrol for patients after oral implantology. Biomed Res 29: 18411844. https://doi.org/10.4066/biomedicalresearch.29-18-398

Bass TM, Weinkove D, Houthoofd K, Gems D, Partridge L (2007) Effects of resveratrol on lifespan in Drosophila melanogaster and Caenorhabditis elegans. Mech Ageing Dev 128: 546-552. https://doi. org/10.1016/j.mad.2007.07.007

Baur JA, Pearson KJ, Price NL, Jamieson HA, Lerin C, Kalra A, Prabhu VV, Allard JS, Lopez-Lluch G, Lewis K, Pistell PJ, Poosala S, Becker KG, Boss O, Gwinn D, Wang M, Ramaswamy S, Fishbein KW, Spencer RG, Lakatta EG, Le Couteur D, Shaw RJ, Navas P, Puigserver P, Ingram DK, de Cabo R, Sinclair DA (2006) Resveratrol improves health and survival of mice on a high-calorie diet. $\mathrm{Na}$ ture 444: 337-342. https://doi.org/10.1038/nature05354

Bereswill S, Muñoz M, Fischer A, Plickert R, Haag LM, Otto B, Kühl AA, Loddenkemper C, Göbel UB, Heimesaat MM (2010) Antiinflammatory effects of resveratrol, curcumin and simvastatin in acute small intestinal inflammation. PLoS One 5: e15099. https:// doi.org/10.1371/journal.pone.0015099

Berman AY, Motechin RA, Wiesenfeld MY, Holz MK (2017) The therapeutic potential of resveratrol: a review of clinical trials. NPJ Precis Oncol 1. https://doi.org/10.1038/s41698-017-0038-6

Bo S, Gambino R, Ponzo V, Cioffi I, Goitre I, Evangelista A, Ciccone G, Cassader M, Procopio M. (2018) Effects of resveratrol on bone health in type 2 diabetic patients. A double-blind randomizedcontrolled trial. Nutr Diabetes 8: 51. https://doi.org/10.1038/s41387018-0059-4

Bobermin LD, Souza DO, Gonçalves CA, Quincozes-Santos A (2018) Resveratrol prevents ammonia-induced mitochondrial dysfunction and cellular redox imbalance in C6 astroglial cells. Nutr Neurosci 21: 276-285. https://doi.org/10.1080/1028415X.2017.1284375

Bonsack F, Alleyne CH Jr, Sukumari-Ramesh S (2017) Resveratrol attenuates neurodegeneration and improves neurological outcomes after intracerebral hemorrhage in mice. Front Cell Neurosci 11: 228. https://doi.org/10.3389/fncel.2017.00228

Brown VA, Patel KR, Viskaduraki M, Crowell JA, Perloff M, Booth TD, Vasilinin G, Sen A, Schinas AM, Piccirilli G, Brown K, Steward WP, Gescher AJ, Brenner DE (2010) Repeat dose study of the cancer chemopreventive agent resveratrol in healthy volunteers: safety, pharmacokinetics, and effect on the insulin-like growth factor axis. Cancer Res 70: 9003-9011. https://doi.org/10.1158/00085472.CAN-10-2364

Buttari B, Profumo E, Facchiano F, Ozturk EI, Segoni L, Saso L, Riganò R (2013) Resveratrol prevents dendritic cell maturation in response to advanced glycation end products. Oxid Med Cell Longev 2013: 574029. https://doi.org/10.1155/2013/574029

Caruso F, Tanski J, Villegas-Estrada A, Rossi M (2004) Structural basis for antioxidant activity of trans-resveratrol: ab initio calculations and crystal and molecular structure. I Agric Food Chem 52: 7279-7285. https://doi.org/10.1021/if048794e

Chen CY, Kao CL, Liu CM (2018) The cancer prevention, anti-inflammatory and anti-oxidation of bioactive phytochemicals targeting the TLR4 signaling pathway. Int J Mol Sci 19. https://doi.org/10.3390/ ijms19092729

Cheng K, Song Z, Zhang H, Li S, Wang C, Zhang L, Wang T (2019) The therapeutic effects of resveratrol on hepatic steatosis in high-fat diet-induced obese mice by improving oxidative stress, inflamma- 
tion and lipid-related gene transcriptional expression. Med Mol Morphol in press. https://doi.org/10.1007/s00795-019-00216-7

Ciddi V, Dodda D (2014) Therapeutic potential of resveratrol in diabetic complications: In vitro and in vivo studies. Pharmacol Rep 66: 799-803. https://doi.org/10.1016/j.pharep.2014.04.006

Corpas R, Griñán-Ferré C, Rodríguez-Farré E, Pallàs M, Sanfeliu C (2018) Resveratrol induces brain resilience against Alzheimer neurodegeneration through proteostasis enhancement. Mol Neurobiol in press. https://doi.org/10.1007/s12035-018-1157-y

Corrêa MG, Absy S, Tenenbaum H, Ribeiro FV, Cirano FR, Casati MZ, Pimentel SP (2018) Resveratrol attenuates oxidative stress during experimental periodontitis in rats exposed to cigarette smoke inhalation. J Periodontal Res in press. https://doi.org/10.1111/ jre.12622

de Vries K, Strydom M, Steenkamp V (2018) Bioavailability of resveratrol: possibilities for enhancement. J Herb Med 11: 71-79. https:// doi.org/10.1016/j.hermed.2017.09.002

Diao J, Wei J, Yan R, Fan G, Lin L, Chen M (2018) Effects of resveratrol on regulation on UCP2 and cardiac function in diabetic rats. $J$ Physiol Biochem in press. https://doi.org/10.1007/s13105-018-0648-7

Erkan SO, Tuhanioğlu B, Gürgen SG, Özdaş T, Taştekin B, Pelit A, Görgülü O (2018) The effect of resveratrol on the histologic characteristics of the cochlea in diabetic rats. Laryngoscope in press. https://doi.org/10.1002/lary.27253

Euba B, López-López N, Rodríguez-Arce I, Fernández-Calvet A, Barberán M, Caturla N, Martí S, Díez-Martínez R, Garmendia J (2017) Resveratrol therapeutics combines both antimicrobial and immunomodulatory properties against respiratory infection by nontypeable Haemophilus influenzae. Sci Rep 7: 12860. https://doi.org/10.1038/ s41598-017-13034-7

Farrokhi E, Ghatreh-Samani K, Salehi-Vanani N, Mahmoodi A (2018) The effect of resveratrol on expression of matrix metalloproteinase 9 and its tissue inhibitors in vascular smooth muscle cells. ARYA Atheroscler 14: 157-162. https://doi.org/10.22122/arya.v14i4.1484

Farzaei MH, Rahimi R, Nikfar S, Abdollahi M (2018) Effect of resveratrol on cognitive and memory performance and mood: A meta-analysis of 225 patients. Pharmacol Res 128: 338-344. https://doi. org/10.1016/j.phrs.2017.08.009

LaFoya B, Munroe JA, Albig AR (2019) A comparison of resveratrol and other polyphenolic compounds on Notch activation and endothelial cell activity. PLoS One 14: e0210607. https://doi. org/10.1371/journal.pone.0210607

Fu S, Lv R, Wang L, Hou H, Liu H, Shao S (2018) Resveratrol, an antioxidant, protects spinal cord injury in rats by suppressing MAPK pathway. Saudi J Biol Sci 25: 259-266. https://doi.org/10.1016/j. sibs.2016.10.019

Galiniak S, Krawczyk-Marć I, Sęk-Mastej A, Leksa N, Biesiadecki M, Orkisz S (2017) Clinical aspects of protein glycation. Eur J Clin Exp Med 15: 263-267. https://doi.org/10.15584/ejcem.2017.3.10

Gambini J, Inglés M, Olaso G, Lopez-Grueso R, Bonet-Costa V, Gimeno-Mallench L, Mas-Bargues C, Abdelaziz KM, Gomez-Cabrera MC, Vina J, Borras C (2015) Properties of resveratrol: in vitro and in vivo studies about metabolism, bioavailability, and biological effects in animal models and humans. Oxid Med Cell Longev 2015: 837042. https://doi.org/10.1155/2015/837042

Ginés C, Cuesta S, Kireev R, García C4 Rancan L, Paredes SD, Vara E, Tresguerres JAF (2017) Protective effect of resveratrol against inflammation, oxidative stress and apoptosis in pancreas of aged SAMP8 mice. Exp Gerontol 90: 61-70. https://doi.org/10.1016/j. exger.2017.01.021

Gokce EH, Korkmaz E, Dellera E, Sandri G, Bonferoni MC, Ozer O (2012) Resveratrol-loaded solid lipid nanoparticles versus nanostructured lipid carriers: Evaluation of antioxidant potential for dermal applications. Int J Nanomed 7: 1841-1850. https://doi.org/10.2147/ IJN.S29710

Gorga A, Rindone GM, Regueira M, Pellizzari EH, Camberos MC, Cigorraga SB, Riera MF, Galardo MN (2018) Effect of resveratrol on Sertoli cell proliferation. J Cell Biochem 119: 10131-10142. https://doi.org/10.1002/jcb. 27350

Gülçin I (2010) Antioxidant properties of resveratrol: A structure-activity insight. Innov Food Sci Emerg Technol 11: 210-218. https://doi. org/10.1016/j.ifset.2009.07.002

Guzmán L, Balada C, Flores G, Álvarez R, Knox M, Vinet R, Martínez JL (2018) t-Resveratrol protects against acute high glucose damage in endothelial cells. Plant Foods Hum Nutr 73: 235-240. https:// doi.org/10.1007/s11130-018-0683-0

Hallajian F, Ghasmi M, Abedi SM, Behzadi R, Hayati E, Sadeghzadeh N, Rezazadeh F, Karimi H (2018) Evaluation of the effect of resveratrol and doxorubicin on $99 \mathrm{~m}$ Tc-MIBI uptake in breast Cancer cell xenografts in mice. Cancer Biother Radiopharm 33: 403-410. https://doi.org/10.1089/cbr.2018.2523

Hara T, Kin A, Aoki S, Nakamura S, Shirasuna K, Kuwayama T, Iwata H (2018) Resveratrol enhances the clearance of mitochondrial damage by vitrification and improves the development of vitrifiedwarmed bovine embryos. PLOS One 13: e0204571. https://doi. org/10.1371/journal.pone.0204571
Hasan M, Bae H (2017) An overview of stress-induced resveratrol synthesis in grapes: perspectives for resveratrol-enriched grape products. Molecules 22. https://doi.org/10.3390/molecules22020294

He T, Xiong J, Nie L, Yu Y, Guan X, Xu X, Xiao T, Yang K, Liu L, Zhang D, Huang Y, Zhang J, Wang J, Sharma K, Zhao J (2016) Resveratrol inhibits renal interstitial fibrosis in diabetic nephropathy by regulating AMPK/NOX4/ROS pathway. J Mol Med (Berl) 94: 1359-1371. https://doi.org/10.1007/s00109-016-1451-y

Higashi Y, Higashi K, Mori A, Sakamoto K, Ishii K, Nakahara T (2018) Anti-cataract effect of resveratrol in high-glucose-treated streptozotocin-induced diabetic rats. Biol Pharm Bull 41: 1586-1592. https://doi.org/10.1248/bpb.b18-00328

Hou Y, Wang K, Wan W, Cheng Y, Pu X, Ye X (2018) Resveratrol provides neuroprotection by regulating the JAK2/STAT3/PI3K/ $\mathrm{AKT} / \mathrm{mTOR}$ pathway after stroke in rats. Genes Dis 5: 245-255. https://doi.org/10.1016/j.gendis.2018.06.001

Huo X, Zhang T2, Meng Q1, Li C3, You B (2019) Resveratrol effects on a diabetic rat model with coronary heart disease. Med Sci Monit 25: 540-546. https://doi.org/10.12659/MSM.910996

Hussain SA, Marouf BH, Ali ZS, Ahmmad RS (2018) Efficacy and safety of co-administration of resveratrol with meloxicam in patients with knee osteoarthritis: a pilot interventional study. Clin Interv Aging 13: 1621-1630. https://doi.org/10.2147/CIA.S172758

Hussein MM, Mahfouz MK (2016) Effect of resveratrol and rosuvastatin on experimental diabetic nephropathy in rats. Biomed Pharmacother 82: 685-692. https://doi.org/10.1016/j.biopha.2016.06.004

Jardim FR, de Rossi FT, Nascimento MX, da Silva Barros RG, Borges PA, Prescilio IC, de Oliveira MR (2018) Resveratrol and brain mitochondria: a review. Mol Neurobiol 55: 2085-2101. https://doi. org/10.1007/s12035-017-0448-z

Johnson AA, Riehle MA (2015) Resveratrol fails to extend life span in the mosquito Anopheles stephensi. Rejuvenation Res 18: 473-478. https://doi.org/10.1089/rej.2015.1670

Kapetanovic IM, Muzzio M, Huang Z, Thompson TN, McCormick DL (2011) Pharmacokinetics, oral bioavailability, and metabolic profile of resveratrol and its dimethylether analog, pterostilbene, in rats. Cancer Chemother Pharmacol 68: 593-601. https://doi.org/10.1007/ s00280-010-1525-4

Khan H, Khan MS, Ahmad S (2018) The in vivo and in vitro approaches for establishing a link between advanced glycation end products and lung cancer. J Cell Biochem 119: 9099-9109. https:// doi.org/10.1002/jcb. 27170

Khazaei M, Karimi J, Sheikh N, Goodarzi MT, Saidijam M, Khodadadi I, Moridi H (2016) Effects of resveratrol on receptor for advanced glycation end products (rage) expression and oxidative stress in the liver of rats with type 2 diabetes. Phytother Res 30: 66-71. https:// doi.org/10.1002/ptr.5501

Kumaran MS, Dabas G, Kapadia AB, Parsad D (2018) Resveratrolinduced thrombocytopenia: Inadvertent side-effect of a commonly used antioxidant. Dermatol Ther 31. https://doi.org/10.1111/ dth. 12578

Landau D, Haghiac M, Calabuig-Navarro V, Minimum J, O’TierneyGinn PF (2017) Potential adverse effects of resveratrol: findings in human placental explants. Am J Obstet Gynecol 216: S317. https:// doi.org/10.1016/j.ajog.2016.11.273

la Porte C, Voduc N, Zhang G, Seguin I, Tardiff D, Singhal N, Cameron DW (2010) Steady-State pharmacokinetics and tolerability of trans-resveratrol $2000 \mathrm{mg}$ twice daily with food, quercetin and alcohol (ethanol) in healthy human subjects. Clin Pharmacokinet 49: 449-454. https://doi.org/10.2165/11531820-000000000-00000

Lee YE, Kim JW, Lee EM, Ahn YB, Song KH, Yoon KH, Kim HW, Park CW, Li G, Liu Z, Ko SH (2012) Chronic resveratrol treatment protects pancreatic islets against oxidative stress in $\mathrm{db} / \mathrm{db}$ mice. PLoS One 7: e50412. https://doi.org/10.1371/journal.pone.0050412

Li C, Wu W, Jiao G, Chen Y, Liu H (2018) Resveratrol attenuates inflammation and reduces matrix-metalloprotease expression by inducing autophagy via suppressing the Wnt/b-catenin signalling pathway in IL-1b-induced osteoarthritis chondrocytes. RSC $A d v$ 8: 20202. https://doi.org/10.1039/c8ra00993g

Li N, Du Z, Shen Q, Lei Q, Zhang Y, Zhang M, Hua J (2017) Resveratrol enhances self-renewal of mouse embryonic stem cells. J Cell Biochem 118: 1928-1935. https://doi.org/10.1002/jcb.25942

Li YR, Li S, Lin CC (2018) Effect of resveratrol and pterostilbene on aging and longevity. Biofactors 44: 69-82. https://doi.org/10.1002/ biof. 1400

Liang QX, Lin YH, Zhang CH, Sun HM, Zhou L, Schatten H, Sun QY, Qian WP (2018) Resveratrol increases resistance of mouse oocytes to postovulatory aging in vivo. Aging (Albany NY) 10: 15861596. https://doi.org/10.18632/aging.101494

Liguori I, Russo G, Curcio F, Bulli G, Aran L, Della-Morte D, Gargiulo G, Testa G, Cacciatore F, Bonaduce D, Abete P (2018) Oxidative stress, aging, and diseases. Clin Interv Aging 13: 757-772. https://doi.org/10.2147/CIA.S158513

Lin YT, Wu YC, Sun GC, Ho CY, Wong TY, Lin CH, Chen HH, Yeh TC, Li CJ, Tseng CJ, Cheng PW (2018) Effect of resveratrol on reactive oxygen species-induced cognitive impairment in rats with an- 
giotensin II-induced early Alzheimer's disease. I Clin Med 7. https:/ / doi.org/10.3390/jcm7100329

Ling L, Gu S, Cheng Y (2017) Resveratrol activates endogenous cardiac stem cells and improves myocardial regeneration following acute myocardial infarction. Mol Med Rep 15: 1188-1194. https://doi. org/10.3892/mmr.2017.6143

Liu FC, Hung LF, Wu WL, Chang DM, Huang CY, Lai JH, Ho LJ (2010) Chondroprotective effects and mechanisms of resveratrol in advanced glycation end products-stimulated chondrocytes. Arthritis Res Ther 12: R167. https://doi.org/10.1186/ar3127

Liu T, Ma Y, Zhang R, Zhong H, Wang L, Zhao J, Yang L, Fan X (2019) Resveratrol ameliorates estrogen deficiency-induced depression- and anxiety-like behaviors and hippocampal inflammation in mice. Psychopharmacology (Berl) in press. https://doi.org/10.1007/ s00213-018-5148-5

Liu T, Qi H, Ma L, Liu Z, Fu H, Zhu W, Song T, Yang B, Li G (2015) Resveratrol attenuates oxidative stress and extends life span in the annual fish Nothobranchius guentheri. Rejuvenation Res 18: 225233. https://doi.org/10.1089/rej.2014.1618

Liu Y, He XQ, Huang X, Ding L, Xu L, Shen YT, Zhang F, Zhu MB, Xu BH, Qi ZQ, Wang HL' (2013) Resveratrol protects mouse oocytes from methylglyoxal-induced oxidative damage. PLoS One 8: e77960. https://doi.org/10.1371/journal.pone.0077960

Lopez MS, Dempsey RJ, Vemuganti R (2015) Resveratrol neuroprotection in stroke and traumatic CNS injury. Neurochem Int 89: 75-82. https://doi.org/10.1016/j.neuint.2015.08.009

Lucas J, Hsieh TC, Halicka HD, Darzynkiewicz Z, Wu JM (2018) Upregulation of PDL1 expression by resveratrol and piceatannol in breast and colorectal cancer cells occurs via HDAC3/p300mediated NFxB signaling. Int J Oncol 53: 1469-1480. https://doi.org/10.3892/ ijo. 2018.4512

Ma C, Wang Y, Dong L, Li M, Cai W (2015) Anti-inflammatory effect of resveratrol through the suppression of NF-xB and JAK/STAT signalling pathways. Acta Biocbim Biophys Sin (Shanghai) 47: 207-213. https://doi.org/10.1093/abbs/gmu135

Ma X, Sun Z, Liu Y, Jia Y, Zhang B, Zhang J (2013) Resveratrol improves cognition and reduces oxidative stress in rats with vascular dementia. Neural Regen Res 8: 2050-2059. https://doi.org/10.3969/j. issn.1673-5374.2013.22.004

Marier JF, Vachon P, Gritsas A, Zhang J, Moreau JP, Ducharme MP (2002) Metabolism and disposition of resveratrol in rats: extent of absorption, glucuronidation, and enterohepatic recirculation evidenced by a linked-rat model. I Pharmacol Exp Ther 302: 369-373. PMID: 12065739

Marouf BH, Hussain SA, Ali ZS, Ahmmad RS (2018) Resveratrol supplementation reduces pain and inflammation in knee osteoarthritis patients treated with meloxicam: A randomized placebo-controlled study. J Med Food in press. https://doi.org/10.1089/jmf.2017.4176

Marx W, Kelly JT, Marshall S, Cutajar J, Annois B, Pipingas A, Tierney A, Itsiopoulos C (2018) Effect of resveratrol supplementation on cognitive performance and mood in adults: a systematic literature review and meta-analysis of randomized controlled trials. Nutr Rev 76: 432-443. https://doi.org/10.1093/nutrit/nuy010

Matough FA, Budin SB, Hamid ZA, Alwahaibi N, Mohamed J (2012) The role of oxidative stress and antioxidants in diabetic complications. Sultan Oaboos Univ Med J 12: 5-18. PMCID: PMC3286717

Mehdi F, Keihan GS, Asadollah AS, Effat F (2018) The effects of resveratrol, metformin, cold and strength training on the level of perilipin 5 in the heart, skeletal muscle and brown adipose tissues in mouse. Cell Biochem Biophys 76: 471-476. https://doi.org/10.1007/ s12013-018-0860-7

Monteillier A, Voisin A, Furrer P, Allémann E, Cuendet M (2018) Intranasal administration of resveratrol successfully prevents lung cancer in A/J mice. Sci Rep 8: 14257. https://doi.org/10.1038/s41598018-32423-0

Moore A, Beidler J, Hong MY (2018) Resveratrol and depression in animal models: a systematic review of the biological mechanisms. Molecules 23. https://doi.org/10.3390/molecules23092197

Moridi H, Karimi J, Sheikh N, Goodarzi MT, Saidijam M, Yadegarazari R, Khazaei M, Khodadadi I, Tavilani H, Piri H, Asadi S, Zarei S, Rezaei A (2015) Resveratrol-dependent down-regulation of receptor for advanced glycation end-products and oxidative stress in kidney of rats with diabetes. Int J Endocrinol Metab 13: e23542. https:// doi.org/10.5812/ijem.23542

Mukherjee S, Dudley JI, Das DK (2010) Dose-dependency of resveratrol in providing health benefits. Dose Response 8: 478-500. https:// doi.org/10.2203/dose-response.09-015.Mukherjee

Nalagoni CSR, Karnati PR (2016) Protective effect of resveratrol against neuronal damage through oxidative stress in cerebral hemisphere of aluminum and fluoride treated rats. Interdiscip Toxicol 9: 78-82. https://doi.org/10.1515/intox-2016-0009

Namsi A, Nury T, Hamdouni H, Yammine A, Vejux A, Vervandier-Fasseur D, Latruffe N, Masmoudi-Kouki O, Lizard G (2018) Induction of neuronal differentiation of murine N2a cells by two polyphenols present in the Mediterranean diet mimicking neuro- trophins activities: resveratrol and apigenin. Diseases 6. https://doi. org/10.3390/diseases6030067

Novelle MG, Wahl D, Diéguez C, Bernier M, de Cabo R (2015) Resveratrol supplementation: Where are we now and where should we go? Ageing Res Rev 21: 1-15. https://doi.org/10.1016/j. arr.2015.01.002

Ohtsu A, Shibutani Y, Seno K, Iwata H, Kuwayama T, Shirasuna K (2017) Advanced glycation end products and lipopolysaccharides stimulate interleukin-6 secretion via the RAGE/TLR4-NF- $x$ B-ROS pathways and resveratrol attenuates these inflammatory responses in mouse macrophages. Exp Ther Med 14: 4363-4370. https://doi. org/10.3892/etm.2017.5045

Öztürk E, Arslan AKK, Yerer MB, Bishayee A (2017) Resveratrol and diabetes: A critical review of clinical studies. Biomed Pharmacother 95: 230-234. https://doi.org/10.1016/j.biopha.2017.08.070

Pallauf K, Rimbach G, Rupp PM, Chin D, Wolf IM (2016) Resveratrol and lifespan in model organisms. Curr Med Chem 23: 4639-4680. https://doi.org/10.2174/0929867323666161024151233

Peñalva R, Morales J, González-Navarro CJ, Larrañeta E, Quincoces G, Peñuelas I, Irache JM (2018) Increased oral bioavailability of resveratrol by its encapsulation in casein nanoparticles. Int J Mol Sci 19. https://doi.org/10.3390/ijms19092816

Peng L, Jiang D (2018) Resveratrol eliminates cancer stem cells of osteosarcoma by STAT3 pathway inhibition. PLoS One 13: e0205918. https://doi.org/10.1371/journal.pone.0205918

Pinheiro DML, de Oliveira AHS, Coutinho LG, Fontes FL, de Medeiros Oliveira RK, Oliveira TT, Faustino ALF, Lira V, de Melo Campos JTA, Lajus TBP, de Souza SJ, Agnez-Lima LF (2018) Resveratrol decreases the expression of genes involved in inflammation through transcriptional regulation. Free Radic Biol Med 130: 8-22. https://doi.org/10.1016/j.freeradbiomed.2018.10.432

Pinkas A, Aschner M (2016) Advanced glycation end-products and their receptors: related pathologies, recent therapeutic strategies, and a potential model for future neurodegeneration studies. Chem Res Toxicol 29: 707-714. https://doi.org/10.1021/acs.chemrestox $.6 \mathrm{~b} 00034$

Plauth A, Geikowski A, Cichon S, Wowro SJ, Liedgens L, Rousseau M, Weidner C, Fuhr L, Kliem M, Jenkins G, Lotito S, Wainwright LJ, Sauer S (2016) Hormetic shifting of redox environment by pro-oxidative resveratrol protects cells against stress. Free Radic Biol Med 99: 608-622. https://doi.org/10.1016/j.freeradbiomed.2016.08.006

Popat R, Plesner T, Davies F, Cook G, Cook M, Elliott P, Jacobson E, Gumbleton T, Oakervee H, Cavenagh J (2013) A phase 2 study of SRT501 (resveratrol) with bortezomib for patients with relapsed and or refractory multiple myeloma. Br J Haematol 160: 714-717. https://doi.org/10.1111/bjh.12154

Pouyafar A, Zadi Heydarabad M, Aghdam SB, Khaksar M, Azimi A, Rahbarghazi R, Talebi M (2019) Resveratrol potentially increased the tumoricidal effect of doxorubicin on SKOV3 cancer stem cells in vitro. J Cell Biochem in press. https://doi.org/10.1002/jcb.28129

Ramos-Gomez M, Olivares-Marin IK, Canizal-García M, González-Hernández JC, Nava GM, Madrigal-Perez LA (2017) Resveratrol induces mitochondrial dysfunction and decreases chronological life span of Saccharomyces cerevisiae in a glucose-dependent manner. J Bioenerg Biomembr 49: 241-251. https://doi.org/10.1007/ s10863-017-9709-9

Rascon B, Hubbard BP, Sinclair DA, Amdam GV (2012) The lifespan extension effects of resveratrol are conserved in the honey bee and may be driven by a mechanism related to caloric restriction. Aging (Albany NY) 4: 499-508. https://doi.org/10.18632/aging.100474

Rauf A, Imran M, Suleria HAR, Ahmad B, Peters DG, Mubarak MS (2017) A comprehensive review of the health perspectives of resveratrol. Food Funct 8: 4284-4305. https://doi.org/10.1039/c7fo01300k

Rhee SY, Kim YS (2018) The role of advanced glycation end products in diabetic vascular complications. Diabetes Metab J 42: 188-195. https://doi.org/10.4093/dmj.2017.0105

Rivière C, Pawlus AD, Mérillon JM (2012) Natural stilbenoids: distribution in the plant kingdom and chemotaxonomic interest in Vitaceae. Nat Prod Rep 29: 1317-1333. https://doi.org/10.1039/c2np20049j

Roggerio A, Strunz CMC, Pacanaro AP, Leal DP, Takada JY, Avakian SD, Mansur AP (2018) Gene expression of sirtuin-1 and endogenous secretory receptor for advanced glycation end products in healthy and slightly overweight subjects after caloric restriction and resveratrol administration. Nutrients 10. https://doi.org/10.3390/ nu10070937

Sadowska-Bartosz I, Galiniak S, Bartosz G (2014) Kinetics of glycoxidation of bovine serum albumin by glucose, fructose and ribose and its prevention by food components. Molecules 19: 18828-18849. https:/ / doi.org/10.3390/molecules191118828

Safaeinejad Z, Nabiuni M, Peymani M, Ghaedi K, Nasr-Esfahani MH, Baharvand H (2017) Resveratrol promotes human embryonic stem cells self-renewal by targeting SIRT1-ERK signaling pathway. Eur I Cell Biol 96: 665-672. https://doi.org/10.1016/j.ejcb.2017.08.002

Salehi B, Mishra AP, Nigam M, Sener B, Kilic M, Sharifi-Rad M, Fokou PVT, Martins N, Sharifi-Rad J (2018) Resveratrol: A dou- 
ble-edged sword in health benefits. Biomedicines 6. https://doi. org/10.3390/biomedicines6030091

San Hipolito-Luengo A, Alcaide A, Ramos-Gonzalez M, Cercas E, Vallejo S, Romero A, Talero E, Sanchez-Ferrer CF, Motilva V. Peiro C (2017) Dual effects of resveratrol on cell death and proliferation of colon cancer cells. Nutr Cancer 69 1019-1027. https://doi.or $\mathrm{g} / 10.1080 / 01635581.2017 .1359309$

Sattarinezhad A, Roozbeh J, Shirazi Yeganeh B, Omrani GR, Shams M (2018) Resveratrol reduces albuminuria in diabetic nephropathy: A randomized double-blind placebo-controlled clinical trial. Diabetes Metab in press. https://doi.org/10.1016/j.diabet.2018.05.010

Sedlak L, Wojnar W, Zych M, Wyględowska-Promieńska D, MrukwaKominek E, Kaczmarczyk-Sedlak I (2018) Effect of resveratrol, a dietary-derived polyphenol, on the oxidative stress and polyol pathway in the lens of rats with streptozotocin-induced diabetes. Nutrients 10: 1423. https://doi.org/10.3390/nu10101423

Sergides C, Chirilă M, Silvestro L, Pitta D, Pittas A (2016) Bioavailability and safety study of resveratrol $500 \mathrm{mg}$ tablets in healthy male and female volunteers. Exp Ther Med 11: 164-170.

Sgarbi G, Liuzzi F, Baracca A, Solaini G Resveratrol preserves mitochondrial function in a human post-mitotic cell model. I Nutr Biochem 62: 9-17. https://doi.org/10.1016/j.jnutbio.2018.07.017

Sharma C, Suhalka P, Bhatnagar M (2018) Curcumin and resveratrol rescue cortical-hippocampal system from chronic fluoride-induced neurodegeneration and enhance memory retrieval. Int J Neurosici 13: 1-15. https://doi.org/10.1080/00207454.2018.1458727

Shati AA (2018) Resveratrol improves sperm parameter and testicular apoptosis in cisplatin-treated rats: effects on ERK1/2, JNK, and Akt pathways. Syst Biol Reprod Med 3:1-14. https://doi.org/10.1080/ 19396368.2018 .1541114

Shen Y, Xu Z, Sheng Z (2017) Ability of resveratrol to inhibit advanced glycation end product formation and carbohydrate-hydrolyzing enzyme activity, and to conjugate methylglyoxal. Food Chem 216: 153-160. https://doi.org/10.1016/j.foodchem.2016.08.034

Shrikanta A, Kumar A, Govindaswamy V (2015) Resveratrol content and antioxidant properties of underutilized fruits. J Food Sci Technol 52: 383-390. https://doi.org/10.1007/s13197-013-0993-z

Singh R, Barden A, Mori T, Beilin L (2001) Advanced glycation end-products: a review. Diabetologia 44: 129-146. https://doi. org/10.1007/s001250051591

Soleas GJ, Angelini M, Grass L, Diamandis EP, Goldberg DM (2001) Absorption of trans-resveratrol in rats. Methods Ensymol 335: 145154. PMID: 11400363

Staats S, Wagner AE, Kowalewski B, Rieck FT, Soukup ST, Kulling SE, Rimbach G (2018) Dietary resveratrol does not affect life span, body composition, stress response, and longevity-related gene expression in Drosophila melanogaster. Int J Mol Sci 19: 223. https://doi. org/10.3390/ijms19010223

Subramanian M, Goswami M, Chakraborty S, Jawali N (2014) Resveratrol induced inhibition of Escherichia coli proceeds via membrane oxidation and independent of diffusible reactive oxygen species generation. Redox Biol 2: 865-872. https://doi.org/10.1016/j.redox.2014.06.007

Szende B, Tyihak E, Kiraly-Veghely Z (2010) Dose-dependent effect of resveratrol on proliferation and apoptosis in endothelial and tumor cell cultures. Exp Mol Med 32: 88. https://doi.org/10.1038/ emm.2000.16

Švajger U, Jeras M (2012) Anti-inflammatory effects of resveratrol and its potential use in therapy of immune-mediated diseases. Int Rev Immunol 31: 202-222. https://doi.org/10.3109/08830185.2012.665108

Takaoka M (1939) Resveratrol, a new phenolic compound from Veratrum grandiflorum. Nippon Kagaku Kaishi 60: 1090-1100.

Tao L, Ding Q, Gao C, Sun X (2016) Resveratrol attenuates neuropathic pain through balancing pro-inflammatory and anti-inflammatory cytokines release in mice. Int Immunopharmacol 34: 165-172. https://doi.org/10.1016/j.intimp.2016.02.033

Tasatargil A, Tanriover G, Barutcigil A, Turkmen E (2018) Protective effect of resveratrol on methylglyoxal-induced endothelial dysfunction in aged rats. Aging Clin Exp Res in press. https://doi. org/10.1007/s40520-018-0986-x

Taylor EJ, Yu Y, Champer J, Kim J (2014) Resveratrol demonstrates antimicrobial effects against Propionibacterium acnes in vitro. Dermatol Ther (Heidelb) 4: 249-257. https://doi.org/10.1007/s13555-0140063-0

Toniolo L, Fusco P, Formoso L, Mazzi A, Canato M, Reggiani C, Giacomello E (2018) Resveratrol treatment reduces the appearance of tubular aggregates and improves the resistance to fatigue in aging mice skeletal muscles. Exp Gerontol 111: 170-179. https://doi. org/10.1016/j.exger.2018.07.012

Valenzano DR, Terzibasi E, Genade T, Cattaneo A, Domenici L, Cellerino A (2006) Resveratrol prolongs lifespan and retards the onset of age-related markers in a short-lived vertebrate. Curr Biol 16: 296-300. https://doi.org/10.1016/j.cub.2005.12.038

Vasamsetti SB, Karnewar S, Gopoju R, Gollavilli PN, Narra SR, Kumar JM, Kotamraju S (2016) Resveratrol attenuates monocyte-to-macrophage differentiation and associated inflammation via modulation of intracellular GSH homeostasis: Relevance in atherosclerosis. Free Radic Biol Med 96: 392-405. https://doi.org/10.1016/j. freeradbiomed.2016.05.003

Walle T (2011) Bioavailability of resveratrol. Ann N Y Acad Sci 1215: 9-15. https://doi.org/10.1111/j.1749-6632.2010.05842.x

Walter KR, Ford ME, Gregoski MJ, Kramer RM, Knight KD, Spruill L, Nogueira LM, Krisanits BA, Phan V, La Rue AC, Lilly MB, Ambs S, Chan K, Turner TF, Varner H, Singh S, Uribarri J, Garrett-Mayer E, Armeson KE, Hilton EJ, Clair MJ, Taylor MH, Abbott AM, Findlay VJ, Peterson LL, Magwood G, Turner DP (2018) Advanced glycation end products are elevated in estrogen receptor-positive breast cancer patients, alter response to therapy, and can be targeted by lifestyle intervention. Breast Cancer Res Treat in press. https://doi.org/10.1007/s10549-018-4992-7

Wang C, Wheeler CT, Alberico T, Sun X, Seeberger J, Laslo M, Spangler E, Kern B, de Cabo R, Zou S (2013) The effect of resveratrol on lifespan depends on both gender and dietary nutrient composition in Drosophila melanogaster. Age (Dordr) 35: 69-81. https://doi. org/10.1007/s11357-011-9332-3

Wang G, Song X, Zhao L, Li Z, Liu B (2018) Resveratrol prevents diabetic cardiomyopathy by increasing NRF2 expression and transcriptional activity. Biomed Res Int 2018: 2150218. https://doi. org/10.1155/2018/2150218

Wang N, Han Q, Wang G, Ma WP, Wang J, Wu WX, Guo Y, Liu L, Jiang XY, Xie XL, Jiang HQ (2016) Resveratrol protects oxidative stress-induced intestinal epithelial barrier dysfunction by upregulating heme oxygenase-1 expression. Dig Dis Sci 61: 2522-2534. https://doi.org/10.1007/s10620-016-4184-4

Wang XL, Li T, Li JH, Miao SY, Xiao XZ (2017) The effects of resveratrol on inflammation and oxidative stress in a rat model of chronic obstructive pulmonary disease. Molecules 22. https://doi. org $/ 10.3390 /$ molecules22091529

Wattroba M, Szukiewicz D (2016) The role of sirtuins in aging and age-related diseases. Adv Med Sci 61: 52-62. https://doi. org/10.1016/j.advms.2015.09.003

Wu MY, Yiang GT, Lai TT, Li CJ (2018) The oxidative stress and mitochondrial dysfunction during the pathogenesis of diabetic retinopathy. Oxid Med Cell Longev 2018: 3420187. https://doi. org/10.1155/2018/3420187

Wu S, Huang J (2017) Resveratrol alleviates Staphylococcus aureus pneumonia by inhibition of the NLRP3 inflammasome. Exp Ther Med 14: 6099-6104. https://doi.org/10.3892/etm.2017.5337

Wu X, Xu Y, Zhu B, Liu Q, Yao Q, Zhao G (2018) Resveratrol induces apoptosis in SGC-7901 gastric cancer cells. Oncol Lett 16: 2949-2956. https://doi.org/10.3892/ol.2018.9045

Xia Y, Xiao HT, Liu K, Zhang HJ, Tsang SW (2018) Resveratrol ameliorates the severity of fibrogenesis in mice with experimental chronic pancreatitis. Mol Nutr Food Res 62: e1700561. https://doi. org/10.1002/mnfr.201700561

Xie J, Liu S, Wu B2 Li G, Rao S, Zou L, Yi Z, Zhang C, Jia T, Zhao S, Schmalzing G, Hausmann R, Nie H, Li G, Liang S (2017) The protective effect of resveratrol in the transmission of neuropathic pain mediated by the P2X7 receptor in the dorsal root ganglia. Neurochem Int 103: 24-35. https://doi.org/10.1016/j.neuint.2016.12.006

Xu K, Liu XF, Ke ZQ, Yao Q, Guo S, Liu C (2018) Resveratrol modulates apoptosis and autophagy induced by high glucose and palmitate in cardiac cells. Cell Physiol Biochem 46: 2031-2040. https://doi. org/10.1159/000489442

Yeh WJ, Hsia SM, Lee WH, Wu CH (2017) Polyphenols with antiglycation activity and mechanisms of action: A review of recent findings. J Food Drug Anal 25: 84-92. https://doi.org/10.1016/j. jfda.2016.10.017

Yılmaz Z, Kalaz EB, Aydın AF, Olgaç V, Doğru-Abbasoğlu S, Uysal M, Koçak-Toker N (2018) The effect of resveratrol on glycation and oxidation products in plasma and liver of chronic methylglyoxal-treated rats. Pharmacol Rep 70: 584-590. https://doi.org/10.1016/j. pharep.2017.12.005

Yuan D, Liu XM, Fang Z, Du LL, Chang J, Lin SH (2018) Protective effect of resveratrol on kidney in rats with diabetic nephropathy and its effect on endoplasmic reticulum stress. Eur Rev Med Pharmacol Sci 22: 1485-1493. https://doi.org/10.26355/eurrev_201803_14497

Zhang T, Chi Y, Kang Y, Lu H, Niu H, Liu W, Li Y (2018) Resveratrol ameliorates podocyte damage in diabetic mice via SIRT1/ PGC- $1 \alpha$ mediated attenuation of mitochondrial oxidative stress. $J$ Cell Physiol in press. https://doi.org/10.1002/jcp.27306

Zhang Y, Luo Z, Ma L, Xu Q, Yang Q, Si L (2010) Resveratrol prevents the impairment of advanced glycosylation end products (AGE) on macrophage lipid homeostasis by suppressing the receptor for AGE via peroxisome proliferator-activated receptor gamma activation. Int J Mol Med 25: 729-734. PMID: 20372816

Zhao W, Huang X, Han X, Hu D, Hu X, Li Y, Huang P, Yao W (2018). Resveratrol suppresses gut-derived NLRP3 inflammasome partly through stabilizing mast cells in a rat model. Mediators Inflamm 2018: 6158671. https://doi.org/10.1155/2018/6158671

Zhao Y, Yuan X, Li X, Zhang Y (2018) Resveratrol significantly inhibits the occurrence and development of cervical cancer by regu- 
lating phospholipid scramblase 1. J Cell Biochem in press. https://doi. org/10.1002/jcb.27335

Zheng X, Jia B, Tian XT, Song X, Wu ML, Kong QY, Li H, Liu J (2018) Correlation of reactive oxygen species levels with resveratrol sensitivities of anaplastic thyroid cancer cells. Oxid Med Cell Longev 2018: 6235417. https://doi.org/10.1155/2018/6235417
Zhou C, Qian W, Ma J, Cheng L, Jiang Z, Yan B, Li J, Duan W, Sun L, Cao J, Wang F, Wu E, Wu Z, Ma Q, Li X (2018) Resveratrol enhances the chemotherapeutic response and reverses the stemness induced by gemcitabine in pancreatic cancer cells via targeting SREBP1. Cell Prolif 19: e12514. https://doi.org/10.1111/cpr.12514

Zhou R, Yi L, Ye X, Zeng X, Liu K, Qin Y, Zhang Q, Mi M (2018) Resveratrol ameliorates lipid droplet accumulation in liver through a SIRT1/ATF6-dependent mechanism. Cell Physiol Biochem 51: 23972420. https://doi.org/10.1159/000495898 